\title{
Environment-specific enhancement of the hyperactivity induced by systemic or intra-VTA morphine injections in rats preexposed to amphetamine
}

\author{
JANE STEWART and PAUL VEZINA \\ Concordia University, Montreal, Canada
}

\begin{abstract}
In Experiment 1, groups of rats were administered 0.1, 1.0, or $3.0 \mathrm{mg} / \mathrm{kg} \mathrm{d}$-amphetamine sulfate, intraperitoneally (i.p.), prior to being placed in an activity box on five occasions, once every third day (conditioning groups); saline injections were given in the home cage on alternate days. Pseudoconditioning groups received saline in the activity box and amphetamine in the home cage. A control group received saline in both environments. Following the amphetamine preexposure phase, all animals were tested in the activity boxes after an i.p. injection of $1.0 \mathrm{mg} / \mathrm{kg}$ morphine sulfate. Conditioning groups that had received either 1.0 or $3.0 \mathrm{mg} / \mathrm{kg}$ amphetamine in the activity boxes had higher levels of activity under morphine than did either the pseudoconditioning groups or the control group, demonstrating environment-specific cross-sensitization between the activity effects of amphetamine and morphine. In Experiment 2, three groups of animals were given four preexposures to amphetamine, as in Experiment 1, and then given a series of tests after bilateral injections of $5.0 \mu \mathrm{g}$ morphine into the ventral tegmental area. Once again, the conditioning group was more active than either of the other two groups. These data suggest that changes in the mesolimbic dopamine system underlie the sensitization of activity from repeated amphetamine and morphine injections. The environment-specific cross-sensitization between the effects of amphetamine and morphine seen in this experiment suggests that the development and expression of drug-induced sensitization can come under the control of conditioned stimuli.
\end{abstract}

Numerous studies have now demonstrated that preexposure to either amphetamine or morphine induces sensitization to the motor activating effects of these drugs. In the case of amphetamine, sensitization of locomotion (Beninger \& Hahn, 1983; Tilson \& Rech, 1973), rotational behavior (Echols, 1977, 1979; Robinson, Becker, \& Presty, 1982), and stereotypy (Eichler, Antelman, \& Black, 1980; Segal \& Mandel, 1974) have all been reported (see Creese, 1983, and Post, 1981, for reviews). The behavioral sensitization seen following amphetamine injections has been shown to be accompanied by longterm enhancement of amphetamine-stimulated dopamine release measured in striatal tissue in vitro (Robinson et al., 1982). In animals showing behavioral sensitization to amphetamine, Nishikawa, Mataga, Takashima, and Toru (1983) found increased dopamine turnover in mesolimbic and striatal terminal regions in response to a methamphetamine injection, although steady-state turnover was unaltered.

Sensitization of the locomotor excitatory effects of morphine, and tolerance of the motor depressant actions, have

This work was supported by a grant awarded to Jane Stewart from the Medical Research Council of Canada (MA6678). Paul Vezina was supported by a scholarship from Fonds de la Recherche en Santé du Québec. The authors' mailing address is: Center for Studies in Behavioral Neurobiology, Department of Psychology, Concordia University, 1455 de Maisonneuve Blvd, Montreal H3G 1M8, Canada. been reported after repeated systemic injections (Babbini \& Davis, 1972; Hinson \& Siegel, 1983; Mucha, Volkovskis, \& Kalant, 1981; Oka \& Hosoya, 1976; Vasko \& Domino, 1978). Interestingly, lesions of the dopamine neurons in the ventral tegmental area (VTA) delay the development of tolerance to the depressant, cataleptic actions of systemic morphine (Hand \& Franklin, 1985). Direct application of morphine to the cell body region of mesolimbic dopamine neurons in the VTA results in hyperactivity, which shows sensitization with repeated application (Joyce \& Iversen, 1979; Vezina \& Stewart, 1984). Similar sensitization has been reported following repeated application of enkephalins to the VTA (Kalivas, Taylor, \& Miller, 1985). Furthermore, Kalivas (1985) has found increased metabolism of dopamine in nucleus accumbens in response to VTA application of enkephalin in animals showing behavioral sensitization. As in the studies with amphetamine, no changes in steady-state dopamine metabolism were detected in animals showing sensitization in response to the drug.

In experiments in which deliberate care has been taken to pair drug exposure exclusively with a distinctive set of environmental stimuli (conditioning experiments), sensitization of both amphetamine and morphine effects has been found to be environment specific. That is, the sensitized responses to the drug are manifested only in the presence of the drug-paired environmental stimuli (see, 
e.g., Tilson \& Rech, 1973; Vezina \& Stewart, 1984). We know of no studies in which tests for environment-specific sensitization of biochemical changes have been conducted. Environment-specific, or conditioned, changes in dopamine turnover have, however, been found following repeated injections of amphetamine or morphine (see Schiff, 1982, for a review).

The conditioned stimulus (CS) control of sensitized responses to these drugs, which act on the central nervous system, is a dramatic and powerful phenomenon. Whatever the neurochemical alterations are that underlie the increased responsiveness that occurs with repeated exposure, environmental stimuli that have been reliably and uniquely paired with exposure to a drug come to be able to gate the expression of both the behavioral and the biochemical effects of the drug. In experiments in which no attempt has been made to pair one set of environmental stimuli exclusively with a drug effect, sensitized responses appear to be elicited by the drug in all parts of the experimental environment, presumably by stimuli common to some aspect of the repeatedly induced drug effects (see Stewart \& Eikelboom, 1987).

The experiments reported here were carried out (1) to investigate possible cross-sensitization between the effects of amphetamine and morphine on locomotor activity, and (2) to determine the degree to which such crosssensitization would come under the control of conditioned stimuli. The accruing evidence that sensitization of the behavioral activating effects of these drugs is mediated by their different actions on common dopamine systems made it seem likely that cross-sensitization would occur. In the first experiment, rats were pretreated with $d$ amphetamine sulfate, i.p., on five occasions. The drug was always given either in an activity box or in the home cage. The response to a low dose of morphine given systemically was then tested in all animals in the activity boxes. This experiment was similar in concept to one previously reported by Bennett and Krank (1985). In the second experiment, the effect of pretreatment with amphetamine on the subsequent response to morphine applied directly to the VTA was investigated.

\section{EXPERIMENT 1}

Method
Subjects
Seventy male Wistar rats (Charles River, Canada), which weighed
$250-300 \mathrm{~g}$ at the beginning of the experiment, were used. The
animals were housed with food and water freely available in a 12-
h-dark/12-h-light reverse-cycle room. All testing was done during
the dark cycle.

\section{Apparatus and Materials}

A bank of 12 activity boxes was used to measure locomotor activity. Each box $(20 \times 41 \times 25 \mathrm{~cm})$ was constructed of pressed wood (rear and two side walls), a wire screen top, a Plexiglas fronthinged door, and a floor of stainless steel rods. Movement was estimated by two photocells positioned $3.5 \mathrm{~cm}$ above the floor and spaced evenly along the longitudinal axis of each box. Activity counts were automatically recorded and totaled by computer every $10 \mathrm{~min}$ for each animal during the course of a session. The boxes were in a room dimly lit with red light; a white noise source was continuously present to mask extraneous noise. A red-light-sensitive Panasonic TV camera was mounted on the wall opposite the boxes and was connected to a monitor and a video tape recorder situated in an adjacent room. In this manner, all animals could be viewed and all or part of a session could be recorded for future scoring.

d-Amphetamine sulfate (Smith, Kline, \& French, Canada) and morphine sulfate (B.D.H. Chemicals, Toronto) were prepared in physiological saline and injected intraperitoneally (i.p.) in a 1.0$\mathrm{ml} / \mathrm{kg}$ volume. Saline injections were made in the same volume by the same route.

\section{Design and Procedures}

Amphetamine preexposure phase. The preexposure phase consisted of five 3-day blocks. Six groups of 10 rats each were administered amphetamine $(0.1,1.0$, or $3.0 \mathrm{mg} / \mathrm{kg}$, two groups at each dose) on one day and saline on the alternate injection day of each block. No injections were given on the third day, when all animals remained in their home cages. Each member of each conditioning (Cond) group was given its appropriate amphetamine injection prior to being placed in the activity box for $2 \mathrm{~h}$; these animals received a saline injection in the home cage. Pseudoconditioning (Pseudo) groups were given saline injections in the activity boxes and their assigned amphetamine injections in the home cage. A control group received saline injections in both environments. Half of the animals from each group received their activity-box injection on the first day of each block and their home-cage injection on the second day. The remaining animals received their injections in the reverse order. Thus, the order in which the animals received their activity-box and home-cage injections was counterbalanced for all groups.

Morphine test day. Following the preexposure phase, all animals were injected with $1.0 \mathrm{mg} / \mathrm{kg}$ morphine prior to being placed in the activity boxes, where activity was measured for $2 \mathrm{~h}$. Again, testing was carried out over 2 days of a 3-day block. Animals that had previously received their activity-box injections on the first day of each block in the preexposure phase were tested on the first day. The remaining animals were tested on the second day. No homecage injections were given in this block. Thus, the time since last exposure to the activity box on this test was the same for all animals, and the time since last drug injection was counterbalanced within each group. No treatments were given on the third day of this block.

Saline test day. Following two further 3-day blocks of amphetamine-treatment days, during which the groups were treated as in the first five blocks, all animals were tested in the activity boxes for a 2 -h period following an injection of saline. The counterbalanced design used previously in the morphine test was maintained.

Activity and stereotypy. It was noticed early in the experiment that animals in Group Cond 3.0 had lower activity scores than those in Group Cond 1.0, but that they were engaging in long bouts of stereotypy. It was decided, therefore, at the end of the study to quantify these behaviors on the last amphetamine-treatment day. In addition to the automatic recording of activity every $10 \mathrm{~min}$, animals in the three conditioning groups were observed for $10 \mathrm{sec}$ every 2 min during the first hour and again for $10 \mathrm{~min}$ at the end of the second hour. At the time of each observation, the animal was assigned a single stereotypy score ranging from 0 to 6: 0-asleep or stationary, 1-actively locomoting, 2-predominantly active with bursts of stereotyped sniffing or rearing, 3-stereotyped sniffing along a fixed path, 4-stereotyped sniffing or rearing in one location, 5-stereotyped behavior in one location with bursts of gnaw- 
ing or licking, 6-continual gnawing or licking in one location (Creese \& Iversen, 1973). An animal's score for each 10-min period was the mean of the five scores collected in the 10-min period.

Statistics. The data were analyzed by $t$ tests or by analyses of variance. Subsequent tests for simple main effects and post hoc Scheffé comparisons were made according to Kirk (1968).

\section{Results and Discussion \\ Amphetamine Preexposure Phase}

For purposes of analysis, the activity data were collapsed into first hour and second hour total scores. Figure 1 shows the mean activity scores for all seven groups on each of the 5 amphetamine-preexposure days when they were tested in the activity box. It can be seen that the groups tested under 1.0 and $3.0 \mathrm{mg} / \mathrm{kg}$ amphetamine were more active than all other groups. Analysis of variance carried out on the first-hour scores yielded significant group $[F(6,63)=24.07, p<.001]$ and day $[F(4,24)=16.17, p<.001]$ effects. Post hoc analyses of the source of these effects showed that the Cond 1.0 group was significantly more active than the Cond 3.0 group and all other groups $(p s<.01)$. The Cond 3.0 group was significantly more active than the control and Pseudo groups overall, but differed from the Cond 0.1 group only on Days 2 and 3 ( $p s<.05$ ). There were no significant differences between the Cond 0.1, the Pseudo, and the saline control groups.

In the second hour, both the group effect $[F(6,63)=$ $45.15, p<.001]$ and the group $\times$ day interaction
$[F(4,24)=2.35, p<.001]$ were significant. Here it can be seen that the relative position of the Cond 1.0 and Cond 3.0 groups was changed; the Cond 3.0 group was most active, differing significantly from the Cond 1.0 group and all others $(p s<.01)$. The Cond 1.0 group was significantly more active than the Cond 0.1 and all other groups $(p s<.01)$. None of the other groups differed significantly from each other.

In the first hour of each session, the activity of Group Cond 1.0 remained relatively constant over days, whereas that of Group Cond 3.0 decreased across days $(p<.01)$ when animals in the latter group were observed to be engaging in increased amounts of stereotypy. For further discussion of this decrease, see the Activity and Stereotypy section below. No significant changes were observed in the Cond 0.1 group or the control group; all the Pseudo groups showed small, but significant, changes over days $(p<.01)$. In the second hour, activity in the Cond 3.0 group increased significantly across days $(p<.01)$, providing some evidence that the activity effects of amphetamine were showing sensitization. In the Cond 1.0 group, the day effect was also significant $(p<.05)$, but in this case the increase occurred between Days 1 and 2 .

\section{Morphine Test Day}

The data from this test day, when all groups, regardless of their previous treatment, received $1.0 \mathrm{mg} / \mathrm{kg}$ morphine, are shown in Figure 2. A preliminary analysis comparing the activity of the control group with that of the

\section{FIRST HOUR}

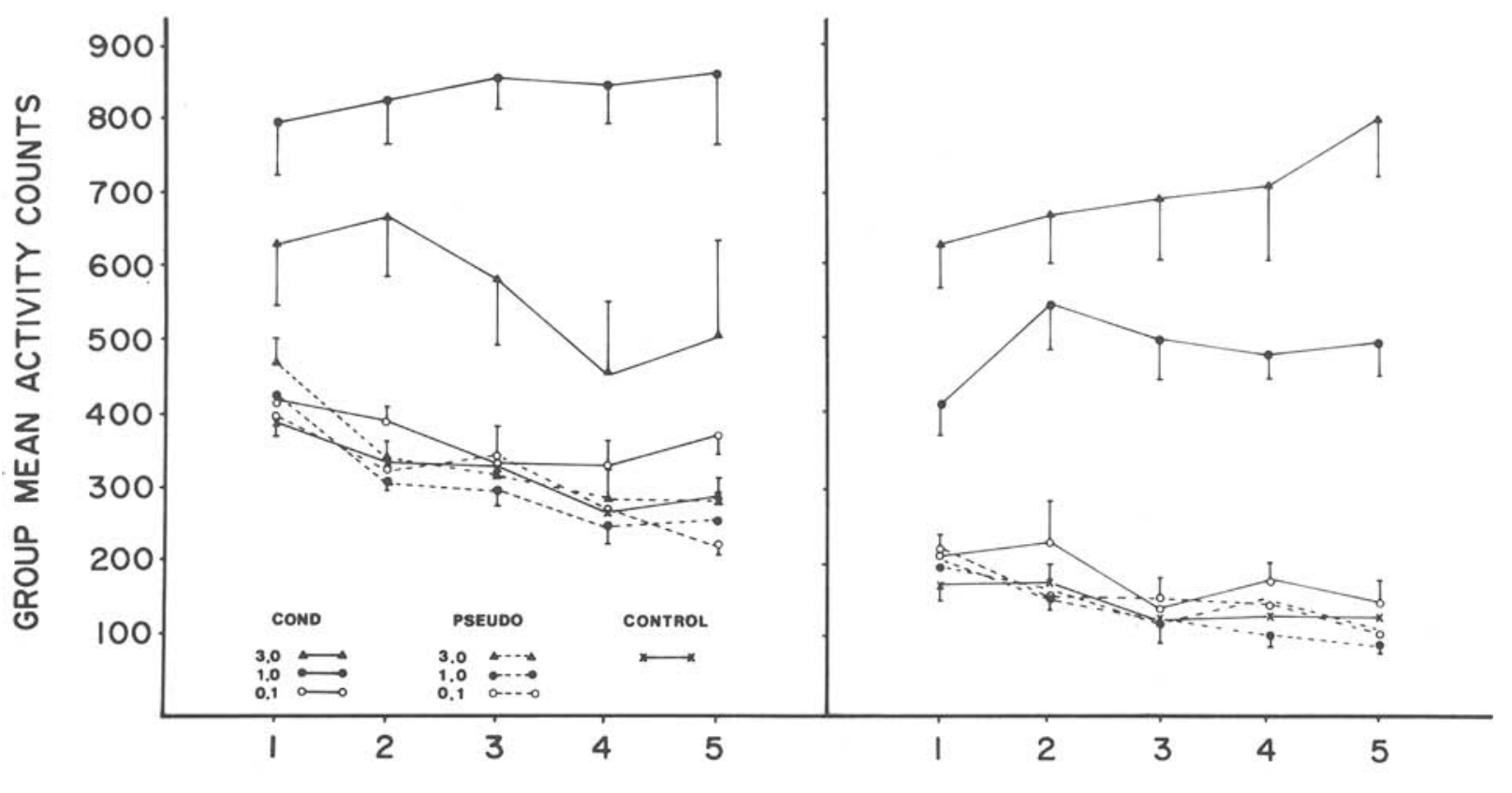

Figure 1. Group mean total activity counts during the first (left panel) and second (right panel) hours of testing in the activity boxes on each of the 5 preexposure days of Experiment 1 . 


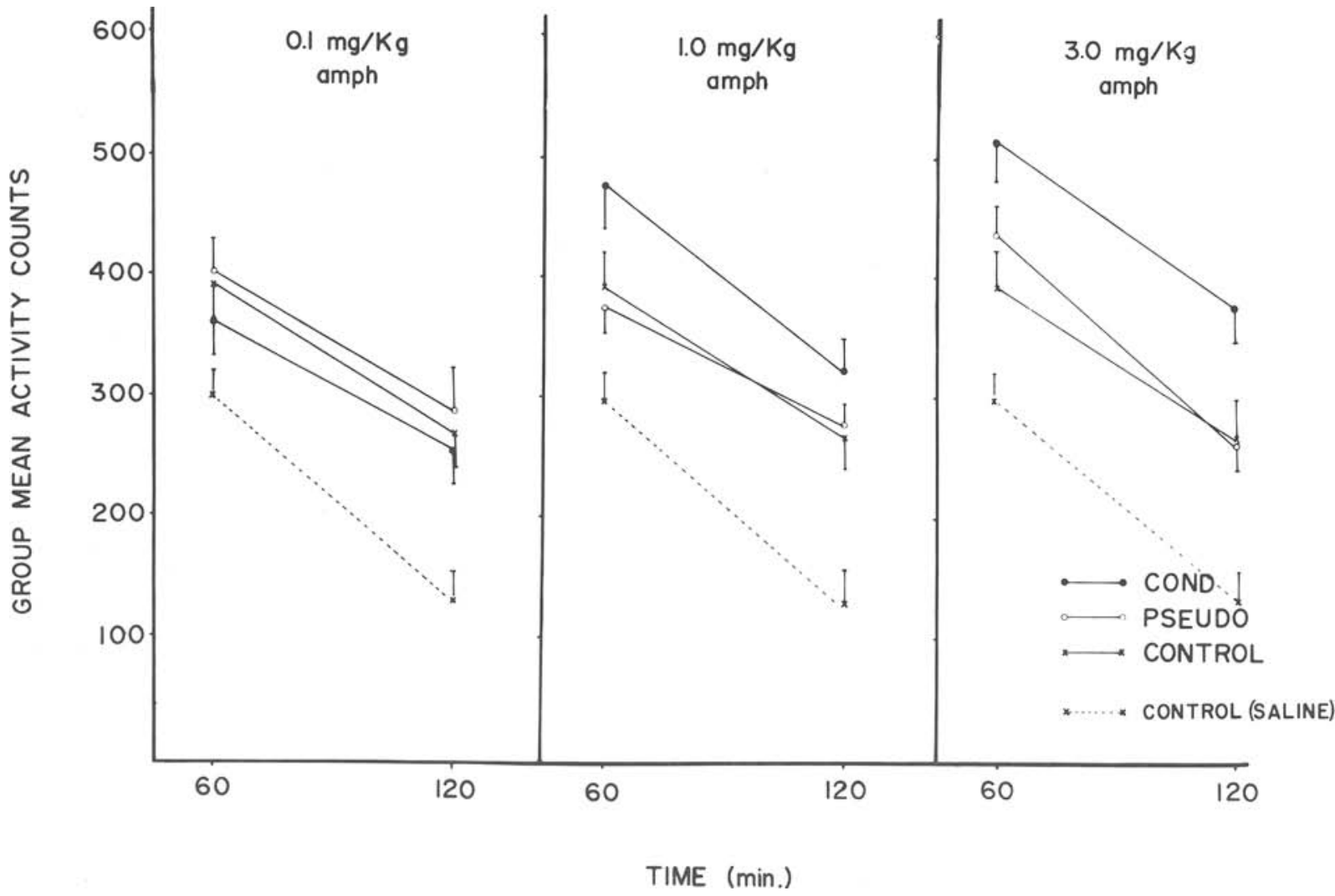

Figure 2. Morphine test day of Experiment 1: Group mean total activity counts for the first and second hours when all animals were injected with $1 \mathrm{mg} / \mathrm{kg}$ morphine. Mean activity counts for the control group when they last received saline injections in the activity boxes are also shown in each panel.

three Pseudo groups showed no significant differences between groups. It was decided, therefore, to perform analyses of variance to compare the activity of each Cond group with that of its own Pseudo group across the two time intervals, as shown in Figure 2. The group mean activity counts obtained for the control group on this test were added to each panel for comparison. It can be seen that both the Cond 1.0 and the Cond 3.0 groups were significantly more active than their respective Pseudo groups overall $[F(1,18)=4.60, p<.05$, and $F(1,18)=6.45$, $p<.02$, respectively]. No significant difference was found between the Cond 0.1 and its corresponding Pseudo group. In all cases, the decrease from the first hour to the second was significant.

Also shown in each panel of Figure 2 are the group mean activity counts obtained for the control-group animals when they last received saline injections in the activity boxes in the preexposure phase. It is clear that morphine increased activity in this group; the mean total activity counts of the control group were significantly higher following the morphine injections than they were following the previous saline injection $[t(9)=5.92$, $p<.001]$.

\section{Saline Test Day}

An analysis, similar to that used for the morphine test, was carried out on the activity scores from the saline test day. The preliminary analysis of variance comparing the activity of the control groups with that of the three Pseudo groups again yielded a nonsignificant group effect. Consequently, the activity of each Cond group was compared with that of its corresponding Pseudo group across the two time intervals. Both the Cond 1.0 and the Cond 3.0 animals were significantly more active than their corresponding Pseudo groups overall $[F(1,18)=7.02$, $p<.05$, and $F(1,16)=11.51, p<.01]$. These data provide evidence for conditioned activity. In both cases, however, the differences between the Cond and the Pseudo groups occurred primarily in the first hour; the means were: Cond 3.0, 438.22, and Pseudo 3.0, 326.22; Cond 1.0, 396.60, and Pseudo 1.0, 285.30. In the second hour, the scores of the Cond groups declined sharply toward those of the Pseudo groups; the means were: Cond 3.0, 249.44, and Pseudo 3.0, 173.89; Cond 1.0, 223.80, and Pseudo 1.0, 176.78. In all of the groups, the activity scores obtained in this test with saline were lower at both time intervals than those in the previous test with morphine. The largest differences between the two tests occurred in the Cond 1.0 and the Cond 3.0 groups in the second hour of testing.

\section{Activity and Stereotypy}

The activity and stereotypy scores for the three Cond groups taken on the final amphetamine-treatment day are 
shown in Figure 3. Note first that, during the first hour, activity was lowest in the Cond 3.0 group, having dropped below that found in the Cond 0.1 group (left panel). The analysis of variance carried out on the activity scores during the first hour revealed significant group $[F(2,27)=$ $47.25, p<.001]$ and time $[F(5,135)=8.18, p<.001]$ effects and a significant group $\times$ time interaction $[F(10,135)=2.94, p<.002]$. The Cond 1.0 group was significantly more active than the other two groups $(p<.01)$, which did not differ statistically from each other. Activity decreased over the first hour in the Cond 3.0 and Cond 0.1 groups, but remained relatively constant in the Cond 1.0 group. The analysis of variance carried out on the activity scores taken in the last $10 \mathrm{~min}$ of the second hour showed a significant difference between groups $[F(2,27)=17.05, p<.001]$. The relative position of groups changed, however, so that the Cond 3.0 group was now significantly more active than either the Cond 1.0 group or the Cond 0.1 group $(p s<.01$ ), which no longer differed significantly. Note that activity increased from the end of the first hour in the Cond 3.0 group, decreased in the Cond 1.0 group, and did not change in the Cond 0.1 group.

As can be seen from Figure 3, during the first hour, when activity was low in Group Cond 3.0 (left panel), stereotypy scores were high (right panel); the opposite was found in Group Cond 1.0. In Group Cond 0.1, both activity and stereotypy scores were low, presumably because the dose was ineffective. Analysis of variance carried out on the stereotypy scores in the first hour revealed significant group $[F(2,27)=159.94, p<.001]$ and time $[F(5,135)=8.42, p<.001]$ effects and a significant group $\times$ time interaction $[F(10,135)=23.20, p<.001]$. Stereotypy increased over the first hour in the Cond 3.0 group and fell slightly in the other two groups. By the

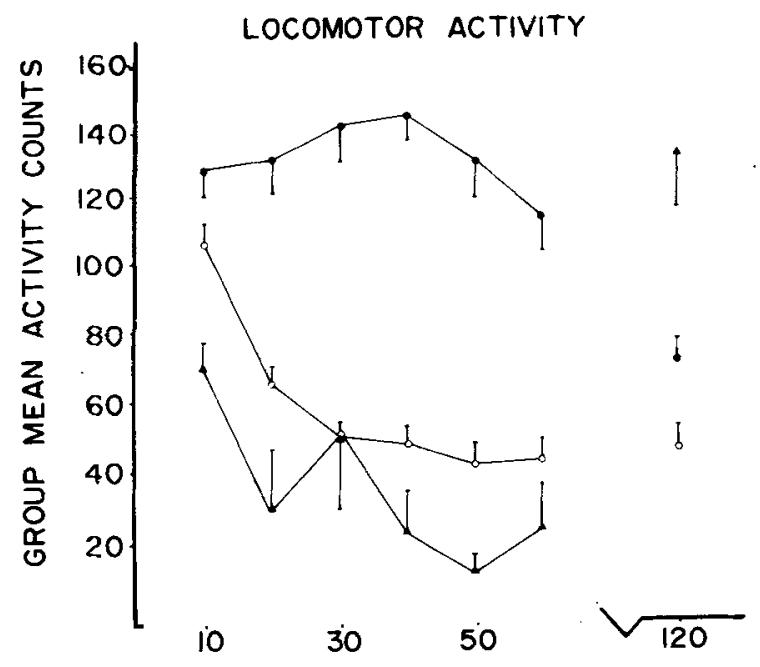

last $10 \mathrm{~min}$ of the second hour, stereotypy scores still differed between groups $[F(2,27)=17.05, p<.001]$. The Cond 3.0 group still had significantly higher scores than either of the other two groups $(p<.01)$.

Several features of the results of Experiment 1 require comment. First, it should be noted that evidence for environment-specific cross-sensitization to morphine occurred following preexposure to 1.0 and $3.0 \mathrm{mg} / \mathrm{kg}$ amphetamine, doses that led to conditioned activity when animals were tested in the activity boxes following saline injections. A question arises, then, about the relationship between the conditioned activity and the environmentspecific sensitization of activity. This issue has been raised by others (e.g., Post, 1981), who have noted that the sensitization effect is something more than the sum of the conditioned effect and the original drug effect. Conditioned activity effects are relatively small in magnitude and, in general, appear only in the early part of the test interval, after which activity scores fall to control-group levels. On the other hand, in animals showing sensitized responses, the hyperactivity is evident throughout the test interval and often appears to grow in magnitude throughout the interval (e.g., Vezina \& Stewart, 1984). Thus, although it is clear that the effect of the drug on activity interacts in some way with the conditioned control of activity by environmental cues (see Stewart \& Eikelboom, 1987), this interaction does not seem to be additive. In the present experiment, the activity differences between the Cond groups and their control groups in the test for conditioning (saline test day) were evident primarily in the first hour, whereas in the test for cross-sensitization (morphine test day), the Cond groups continued to be more active throughout the test session.

A second feature of the results of Experiment 1 that should be noted is that during the amphetamine preex-

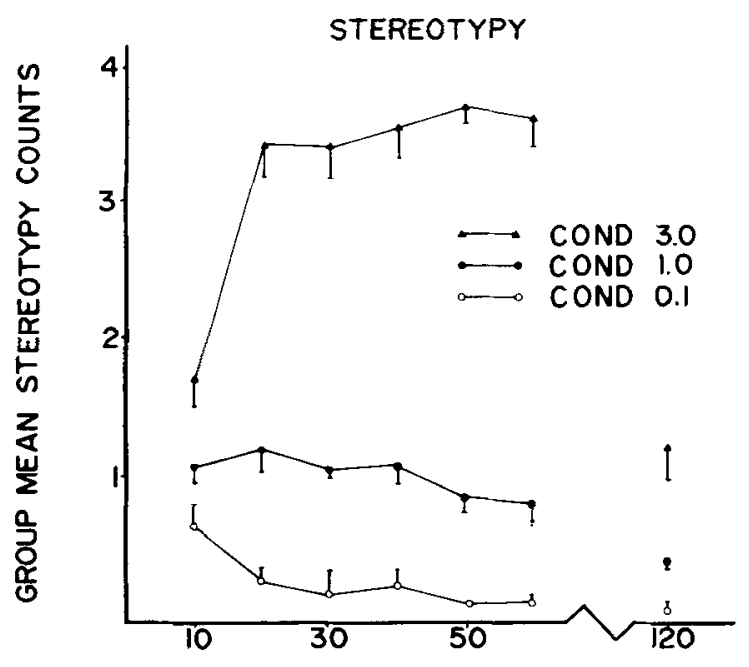

TIME (min.)

Figure 3. Group mean activity (left panel) and stereotypy scores (right panel) obtained with amphetamine by the three conditioning groups on the last day of testing in Experiment 1 . 
posure phase, the nature of the changes in behavior that occurred following repeated injection differed as a function of dose. At the highest dose, $3.0 \mathrm{mg} / \mathrm{kg}$, animals showed progressive decreases in activity in the first hour and progressive increases in the second hour. As was seen in the test in which stereotypy was measured, lower activity scores were reflected in higher stereotypy scores at this high dose. It appears that at the peak of the drug action in the first hour, stereotypy was sensitizing, whereas later, when the drug was being eliminated, the hyperactivity, characteristic of lower doses of amphetamine, was sensitizing. Animals showing such sensitized effects to the drug behaved as if they were receiving an even higher dose of the drug. Furthermore, regardless of the changes in behavior that occurred with repeated exposure to amphetamine, the conditioned effects and the cross-sensitivity to morphine were expressed as hyperactivity (increased locomotion throughout the compartment); on the tests with morphine, animals behaved as if they were receiving a low dose of amphetamine, sufficient to elicit only the increased locomotor activity. Thus, the conditioning and the environmental facilitation of the drug action were not, as is often assumed, directly linked to a specific behavioral response.

Finally, inasmuch as the locomotor activity induced by amphetamine has been shown to be dependent on the integrity of the mesolimbic dopamine system (Kelly, Seviour, \& Iversen, 1975), these observations and those discussed in the introduction strongly suggest that changes in this system, itself, could underlie the enhanced behavioral responsiveness to amphetamine, morphine, and the conditioning stimuli. In Experiment 2, this idea was tested more directly by applying morphine to the cell-body region of the mesolimbic dopamine neurons in the VTA.

\section{EXPERIMENT 2}

\section{Method}

\section{Subjects}

The animals used in this experiment were 250-300-g male Wistar rats obtained from the same supplier as in Experiment 1. They were housed as in Experiment 1. One week after their arrival, all animals were subjected to stereotaxic surgery. Upon histological examination of the brains, some animals were eliminated because neither of the two injector cannula tips was properly situated in the vicinity of the VTA. Accordingly, 46 animals were included in the experiment. Four animals were subsequently eliminated from the analysis of the morphine test phase because the dental-cement mount holding the cannulas to the skull became loose.

\section{Surgery}

One week after arrival, the animals were anesthetized with sodium pentobarbital $(0.85 \mathrm{ml} / \mathrm{kg}$ Somnotol, M.T.C. Pharmaceuticals Ltd.) and stereotaxically implanted with chronic bilateral guide cannulas (22-ga stainless steel tubing) aimed at the VTA and positioned $1 \mathrm{~mm}$ above the final injection site. The cannulas were held in place by dental cement molded around stainless steel screws secured in the skull. The VTA coordinates were: A/P -3.8 from bregma, $\mathrm{L} \pm 0.6$, and $\mathrm{D} / \mathrm{V}-8.9$ from skull. The guide cannulas were implanted at $16^{\circ}$ to the vertical. This steered the guide cannulas around the periventricular gray region and prevented damage to it and penetration of the cerebral aqueduct. Blockers, which were kept in place between treatments, and injector cannulas were made of 28-ga stainless steel.

Following the experiments, all animals were perfused transcardially with saline and Formalin under deep anesthesia. Histological verification of cannula-tip placements was subsequently made on $40-\mu$ thionin-stained coronal sections.

\section{Apparatus and Materials}

The apparatus was the same as that used in Experiment 1. Amphetamine was prepared as before and injected i.p. at a dose of $1.0 \mathrm{mg} / \mathrm{kg}$, in a $1.0-\mathrm{ml} / \mathrm{kg}$ volume. Bilateral intra-VTA injections of morphine $(5 \mu \mathrm{g} / \mathrm{side})$ were made simultaneously in the unrestrained rat. Morphine sulfate was dissolved in sterile $0.9 \%$ saline and microinjected in a volume of $0.5 \mu \mathrm{l} / \mathrm{side}$ over $45 \mathrm{sec}$. The injection cannulas were left in place for an additional $75 \mathrm{sec}$.

\section{Design and Procedure}

Amphetamine preexposure phase. Following a period of at least 1 week for recovery from surgery, the animals were divided into three groups and given four sessions in the activity boxes under the same daily schedule as that used in Experiment 1. Group Cond received an amphetamine injection prior to being placed in the activity box and saline in the home cage. Group Pseudo received saline in the activity boxes and amphetamine in the home cage. The control group received saline in both environments.

Morphine test days. The day following the preexposure phase, animals in all groups were given microinjections of morphine into the VTA and placed in the activity boxes. Three additional activity tests were given at 3-day intervals using the same dose of morphine. The animals were not injected on the intervening days.

\section{Results and Discussion \\ Amphetamine Preexposure Phase}

As in Experiment 1, the Group Cond animals, which received $1.0 \mathrm{mg} / \mathrm{kg}$ amphetamine, i.p., prior to being placed in the activity boxes were more active than the other two groups throughout the preexposure phase. The group mean activity counts during the first and second hours of the test are shown for each of the 4 preexposure days in Figure 4. Analysis of variance carried out on the first-hour scores yielded a significant group effect $[F(2,43)$ $=159.31, p<.001]$ and a significant group $\times$ day interaction $[F(6,129)=7.87, p<.001]$. During the second hour, the group $[F(2,43)=151.10, p<.001]$ and day $[F(3,129)=3.44, p<.05]$ effects and the group $X$ day interaction $[F(6,129)=4.25, p<.001]$ were significant. In both the first and second hours, Group Cond showed increased activity across days, providing strong evidence that the activity effects of amphetamine were sensitizing. Activity in the other two groups declined across days.

\section{Morphine Test Days}

The data from the test days, when all groups, regardless of their previous treatment, received injections of morphine into the VTA, are shown in Figure 5. The analysis of variance carried out to compare the scores of the three groups on the 4 morphine-treatment days showed that in the first hour (left panel), the group $[F(2,39)=$ $4.09, p<.05]$ and the day $[F(3,117)=2.92, p<.05]$ effects were significant. Animals in the Cond group were 


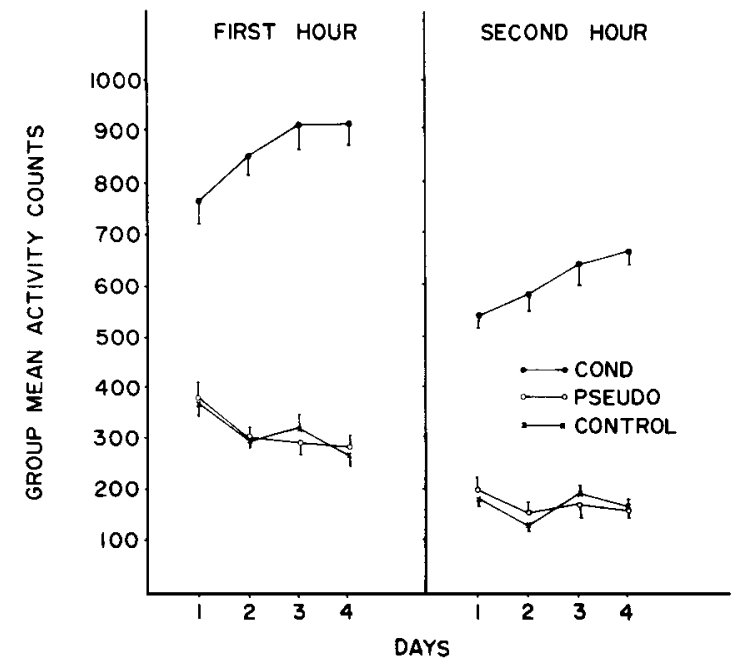

Figure 4. Group mean total activity counts during the first (left panel) and second (right panel) hours of testing in the activity boxes on each of the 4 preexposure days of Experiment 2.

significantly more active overall during this first hour than the animals in the other two groups combined $(p<.05)$, but over the 4 days of morphine treatment, they showed no increase in activity. Scores in the other two groups increased over days, but the increase was significant only in the Pseudo group $(p<.01)$.

During the second hour (right panel), although scores in the Cond group remained highest, the group effect was no longer significant. This disappearance of the group effect may have been due to the fact that during the second hour, although sensitization to the activity effects of mor- phine occurred in all groups over the 4 test days $[F(3,117)$ $=8.44, p<.001]$, it was occurring more rapidly in the Pseudo and control groups. A test for simple main effects showed that the greatest increase occurred in the Pseudo group $(p<.001)$.

The data for the control group from the last salinetreatment day in the activity boxes are shown at the left of each panel. A comparison of the mean total activity scores from the two sessions showed that animals in the control group were significantly more active following their first intra-VTA injection of morphine than they were following the systemic injection of saline $[t(13)=3.42$, $p<.001$ ]. As can be seen from Figure 5, this difference was most evident in the second hour.

In this experiment, the sensitization to the activity effects of amphetamine and the environment-specific crosssensitization to the activity effects of morphine were again observed. In this case, however, when morphine was applied to the VTA, an area where morphine is known to induce activity independent of its depressant actions, the magnitude of the cross-sensitization effect was greater than it was when morphine was administered systemically (Experiment 1 ). In the latter case, initial depressant actions or nonspecific effects of morphine may have partially masked the drug's excitatory actions in animals first exposed to it.

\section{GENERAL DISCUSSION}

In these experiments, animals repeatedly preexposed to amphetamine in the presence of one set of environmental cues showed increased levels of activity in that same

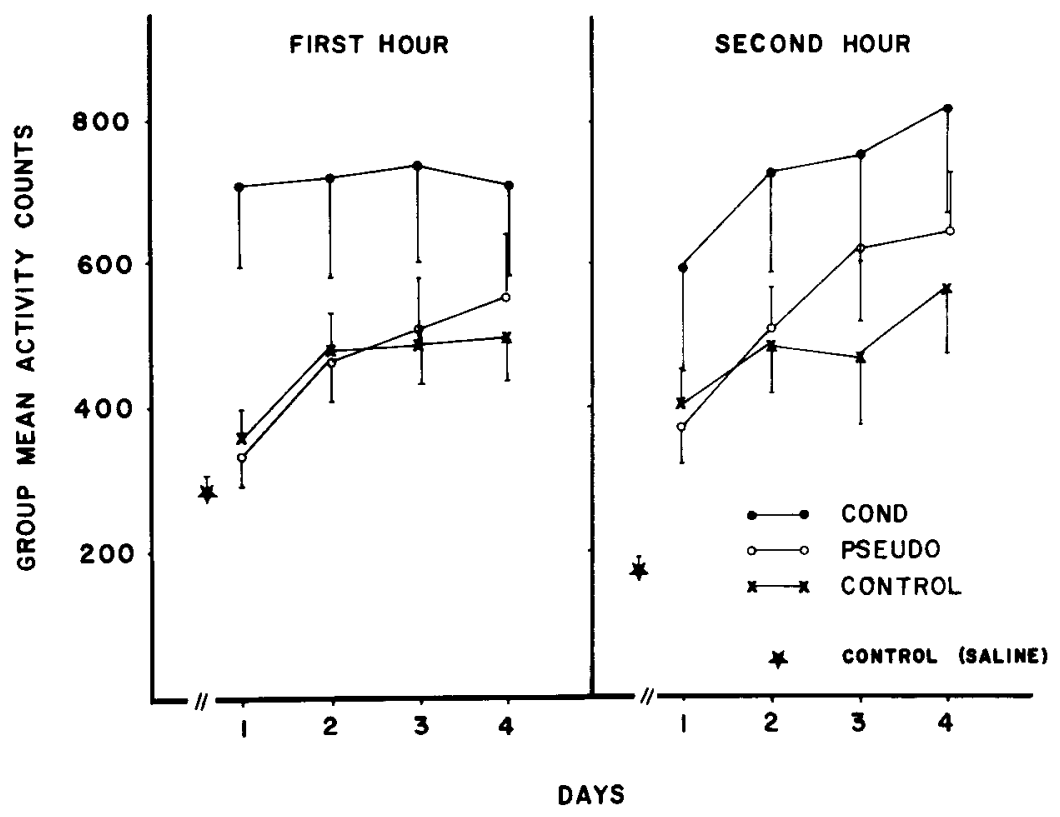

Figure 5. Morphine test days of Experiment 2: Group mean total activity counts during the first (left panel) and second (right panel) hours of each test day when all animals received bilateral microinjections of morphine $(5 \mu \mathrm{g} /$ side) into the VTA. The mean activity counts for the control group from the last saline-treatment day in the activity boxes are shown at the left of each panel. 
environment when they were subsequently administered morphine either systemically or centrally to the VTA. The sensitization of the activity effect of the stimulant drug, amphetamine, seen in this and previous studies, has been found here to show cross-sensitization to the excitatory effects of the opiate drug, morphine, on activity. Because the activity effects of amphetamine are known to depend on the integrity of the mesolimbic dopamine neurons, and because morphine applied to the VTA is known to activate those same neurons and to lead to increased motor activity, it is likely that this system, common to the action of the two drugs, mediates the cross-sensitization. A major feature of the cross-sensitization observed here was that it was manifested only in those animals that were administered morphine in the same environment in which amphetamine had been administered. No evidence for cross-sensitization was found in animals that had previously received amphetamine in an environment different from the test environment. Similar strong stimulus control was seen previously in our work on sensitization to the activity-inducing effects of morphine administered to the VTA (Vezina \& Stewart, 1984), in which, as in the present experiments, one set of environmental cues was explicitly paired with repeated exposure to the drug. How can we account for this stimulus control? What are its implications for an understanding of the changing effectiveness of centrally acting drugs that occurs with repeated exposure? Answers to these questions might arise out of answers to two further questions. What is the nature of the substrate that is changed during sensitization, and how are environmental stimuli involved in the expression of sensitization to a drug effect? It is clear that at present there are no definitive answers to these questions, but evidence does exist that must be taken into account, and that may ultimately bear on an explanation of the phenomenon of environment-specific sensitization.

Considerable evidence exists to suggest that modifications in the functioning of dopamine neurons, themselves, underlie the sensitization to amphetamine and other stimulants and to morphine and other opioids. For example, Kalivas (1985) has found that the increase in metabolism seen in dopamine neurons in response to an intra-VTA injection of enkephalin is greater in animals showing a sensitized behavioral response to such injections than it is in previously untreated animals. Using an in vitro preparation, it has been found that striatal tissue taken from animals previously exposed to repeated injections of amphetamine releases more dopamine to an amphetamine challenge than does tissue from untreated animals (Becker, Beer, \& Robinson, 1984; Robinson et al., 1982). Such evidence suggests that, in animals showing behavioral sensitization, there may be changes in the amount of dopamine available for release and/or accompanying changes in the membrane and associated receptors of the dopamine neuron itself. These functional changes probably involve more than one underlying mechanism, and it is likely that stimulants and opiates do not affect these mechanisms in an identical manner.
One possible mechanism for functional change in these neurons is a change in the sensitivity of the dopamine autoreceptors. It has been known for some time that these autoreceptors, sensitive to released dopamine, control, in part, the firing of the dopamine cell and regulate dopamine synthesis and release. Neurophysiological studies have shown that acute administration of dopamine and other autoreceptor agonists reduces firing in dopamine neurons (see Wang, 1981), whereas following the administration of autoreceptor antagonists, firing in the neuron is more easily elicited and is more frequent and extended in time (Bunney, Walters, Roth, \& Aghajanian, 1973; White \& Wang, 1984). Excessive exposure of autoreceptors to dopamine appears to lead to their downregulation, a situation that would ultimately reduce their inhibitory control of cell firing. It is possible, therefore, that repeated exposure to a drug, or for that matter any other event that leads to excessive dopamine release and increased occupation of autoreceptors, could thereby cause their down-regulation and its ensuing consequences (see, e.g., Muller \& Seeman, 1979). If increased firing and release of dopamine is accompanied by increased synthesis, then the neuron would both be less easily inhibited and release more dopamine when fired. Interestingly, it should be noted again that no changes in steady-state dopamine metabolism have been found in the mesolimbic and striatal terminal fields of animals showing sensitized responses to pharmacological challenge (Kalivas, 1985; Nishikawa et al., 1983); rather, as suggested above, the changes appear to be in the way in which the dopamine neuron responds. In a recent review of the possible mechanisms involved in sensitization of the effects of amphetamine, Robinson and Becker (1986) have argued that although it seems clear that a change in the dopamine neuron itself underlies sensitization, autoreceptor subsensitivity cannot account for all aspects of the phenomenon (see also Riffee \& Wilcox, 1985; Schwartz, Costentin, Martres, Protais, \& Bandry, 1978; Vaughn \& Wilcox, 1982; Walters, Bunney, \& Roth, 1975). They propose other possibilities, such as a shift in the availability of readily releasable dopamine from terminals and the even more interesting possibility of presynaptic facilitation by hyperpolarization of the dopamine terminal via presynaptic input. In this context, however, Mereu, Westfall, and Wang's (1985) recent report that infusion of amphetamine into the nucleus accumbens inhibited the excitability of mesolimbic dopamine neurons and their suggestion that this inhibition is a consequence of dopamine autoreceptormediated hyperpolarization of terminal membranes should be noted.

Consider now the role of environmental stimuli in the behavioral and biochemical expression of sensitization to the effects of a drug. First, it is important to note that the demonstration of a role for environmental stimuli in the development and expression of sensitization requires that exposure to the drug occur repeatedly in the presence of a specific set of environmental stimuli. This is the basic procedure for excitatory conditioning, whereby neutral 
stimuli repeatedly presented in a reliably contingent relationship with an unconditioned stimulus (US) come to be able to elicit responses with components similar to those elicited by the US. In this context, it is important to be aware of the fact that the establishment of a set of stimuli as CSs involves a period of differentiation during which those stimuli that are paired exclusively with the occurrence of the US are discriminated from those that are paired infrequently or not at all with its occurrence, or that are paired equally with its occurrence and nonoccurrence. Furthermore, through this procedure, CSs come not only to be able to elicit responses that mimic those elicited by the US, but, in addition, to facilitate, or to alter, the response to the US (see Zamble, 1973, and Zamble, Hadad, Mitchell, \& Cutmore, 1985, for examples, and Hollis, 1982, for a review). Stimuli that are explicitly unpaired with the US come to have either little or no effect on the response to the US, or actually to inhibit it (see Rescorla, 1969). In the early stages of conditioning, however, before discrimination or differentiation has occurred, stimuli other than the nominal, or intended, CS also elicit responses that mimic the response to the US. ${ }^{1}$

Recent neurophysiological and biochemical experiments on the possible modifications underlying conditioning in simple nervous systems have shown that following repeated presentation of a US there is presynaptic facilitation of sensory neural elements (potential CS elements) that have access to output systems in common with the US. Conditioning, the selective enhancement of the effectiveness of one set of potential CS elements, is thought to be a specialized form of presynaptic facilitation that arises from the simultaneous firing of both the CSstimulated elements and the US-stimulated elements (Kandel et al., 1983; Hawkins \& Kandel, 1984).

Perhaps similar neurobiochemical processes underlie the selective stimulus control of sensitization to the effects of drugs seen in experiments such as the present one, in which deliberate care is taken to pair drug exposure with one set of environmental stimuli and saline with a different set. If such mechanisms were operating, one would not expect to see evidence for selective environmental control of sensitization under conditions in which many features of the experimental environment were paired with both drug and nondrug injections. Under these conditions, all the potential eliciting stimuli would be expected to undergo "presynaptic facilitatory-like" changes as a result of their pairings with the drug exposure. The demonstration of conditioned sensitization requires that there exist stimuli that, because they have been explicitly unpaired with the drug, do not participate in, or perhaps inhibit, the facilitation of the drug action.

In conclusion, it should be noted that in the view outlined here, environmental stimuli are always involved in the expression of the effects of centrally acting drugs in behaving animals. Conditioned environmental stimuli should not be thought of as creating abnormal, artifactual effects that get in the way of true pharmacological effects, but rather as stimuli that, through their history of association with exposure of the organism to a drug, now participate in the selective expression (in the case of sensitization, the selective enhancement) of the drug effect.

\section{REFERENCES}

BaBbINI, M., Davis, W. M. (1972). Time-dose relationships for locomotor activity effects of morphine after acute or repeated treatment. British Journal of Pharmacology, 46, 213-224.

Becker, J. B., Beer, M. E., \& Robinson, T. E. (1984). Striatal dopamine release stimulated by amphetamine or potassium: Influence of ovarian hormones and the light-dark cycle. Brain Research, 311, $157-160$.

Beninger, R. I., \& Hahn, B. L. (1983). Pimozide blocks establishment but not expression of amphetamine-produced environmentspecific conditioning. Science, $220,1304-1306$.

BENNETT, D., \& KRANK, M. D. (1985). Conditioning and amphetamineinduced enhancement of tolerance to the sedative effects of morphine. Canadian Psychologist, 26(2a), 28.

Bunney, B. S., Walters, J. R., Roth, R. H., \& Aghajanian, G. K. (1973). Dopamine neurons: Effect of antipsychotic drugs and amphetamine on single cell activity. Journal of Pharmacology \& Experimen tal Therapeutics, $185,560-571$.

CREESE, I. (1983). Stimulants: Neurochemical, behavioral and clinical perspectives. New York: Raven Press.

CreEse, I., \& IVERSEN, S. D. (1973). Blockage of amphetamine-induced motor stimulation and stereotypy in the adult rat following neonatal treatment with 6-hydroxydopamine. Brain Research, 55, 369-382.

Echols, S. D. (1977). Circling of mice bearing unilateral striatal le sions: Development of increased response to d-amphetamine. Life Sciences, 21, 563-568.

EcHOLS, S. D. (1979). Reverse tolerance to amphetamine of mice bearing unilateral striatal lesions: Effect upon the circling response to apomorphine. Life Sciences, 24, 691-696.

Eichler, A. J., Antelman, S. M., \& Black, C. A. (1980). Amphetamine stereotypy is not a homogeneous phenomenon: Sniffing and licking show distinct profiles of sensitization and tolerance. Psychopharmacology, 68, 287-290.

HaND, T. H., \& FRANKLIN, K. B. J. (1985). Lesions of ventral tegmental dopamine neurons delay the development of tolerance to mor phine catalepsy. Neuroscience Letters, 55, 367-370.

Hawkins, R. D., \& KANDEL, E. R. (1984). Is there a cell-biological alphabet for simple forms of learning? Psychological Review, 91, 375-391.

HINSON, R. E., \& SIEGEL, S. (1983). Anticipatory hyperexcitability and tolerance to the narcotizing effect of morphine in the rat. Behavioral Neuroscience, 97, 759-767.

Hollis, K. L. (1982). Pavlovian conditioning of signal-centered action patterns and autonomic behavior: A biological analysis of function. In J. S. Robenblatt, R. H. Hinde, C. Beer, \& M. Busnel (Eds.), Advances in the study of behavior (Vol. 12, pp. 1-64). New York: Academic Press.

JoYCE, E. M., \& IvERSEN, S. D. (1979). The effect of morphine applied locally to mesencephalic dopamine cell bodies on spontaneous motor activity in the rat. Neuroscience Letters, 14, 207-212.

Kalivas, P. W. (1985). Sensitization to repeated enkephalin administration into the ventral tegmental area of the rat: II. Involvement of the mesolimbic dopamine system. Journal of Pharmacology \& Experimental Therapeutics, 235, 544-555.

Kalivas, P. W., Taylor, S., Miller, J. S. (1985). Sensitization to repeated administration into the ventral tegmental area of the brain: I. Behavioral characterization. Joumal of Pharmacology \& Experimental Therapeutics, 235, 537-543.

Kandel, E. R., Abrams, T., Bernier, L., Carew, T. J., Hawkins, R. D., Schwartz, J. A. (1983). Classical conditioning and sensitization share aspects of the same molecular cascade in Aplysia. Cold Spring Harbor Symposium on Quantitative Biology, 48, 821-830. Kelly, P. H., Seviour, P. W., \& Iversen, S. D. (1975). Ampheta- 
mine and apomorphine responses in the rat following 6-OHDA lesions of the nucleus accumbens septi and corpus striatum. Brain Research, 94, 507-522.

KIRK, R. E. (1968). Experimental design: Procedures for the behavioral sciences. Belmont, CA: Brooks/Cole.

MACKINTOSH, N. J. (1974). The psychology of animal learning. London: Academic Press.

Mereu, G., Westfall, T. C., \& Wang, R. Y. (1985). Modulation of terminal excitability of mesolimbic dopaminergic neurons by damphetamine and haloperidol. Brain Research, 359, 88-96.

Mucha, R. F., Volkovskis, C., \& Kalant, H. (1981). Conditioned increases in locomotor activity produced with morphine as an unconditioned stimulus, and the relation of conditioning to acute morphine effect and tolerance. Journal of Comparative \& Physiological Psychology, 95, 351-362.

Muller, P., \& Seeman, P. (1979). Pre-synaptic subsensitivity as a possible basis for sensitization by long-term dopamine mimetics. European Journal of Pharmacology, 55, 149-157.

Nishikawa, T., Mataga, N., Takashima, M., \& Toru, M. (1983). Behavioral sensitization and relative hyperresponsiveness of striatal and limbic dopaminergic neurons after repeated methamphetamine treatment. European Journal of Pharmacology, 88, 195-203.

OKA, T., \& Hosoy A, E. (1976). Effects of humoral modulators and naloxone on morphine-induced changes in the spontaneous locomotor activity of the rat. Psychopharmacology, 47, 243-248.

Post, R. M. (1981). Central stimulants: Clinical and experimental evidence on tolerance and sensitization. In Y. Israel, F. B. Glaser, H. Kalant, R. E. Popham, W. Schmidt, \& R. G. Smart (Eds.), Research advances in alcohol and drug problems (Vol. 6, pp. 1-65). New York: Plenum Press.

Rescorla, R. A. (1969). Pavlovian conditioned inhibition. Psychological Bulletin, 72, 77-94.

RiffeE, W. H., \& Wilcox, R. E. (1985). Effects of multiple pretreatment with apomorphine and amphetamine on amphetamine-induced locomotor activity and its inhibition by apomorphine. Psychopharmacology, 85, 97-101.

RoBINSON, T. E., \& BECKER, J. B. (1986). Enduring changes in brain and behavior produced by chronic amphetamine administration: $A$ review and evaluation of animal models of amphetamine psychosis. Brain Research Reviews, 11, 157-198.

Robinson, T. E., Becker, J. B., \& Presty, S. K. (1982). Long-term facilitation of amphetamine-induced rotational behavior and striatal dopamine release produced by a single exposure to amphetamine: Sex differences. Brain Research, 253, 231-241.

ScHIF, S. R. (1982). Conditioned dopaminergic activity. Biological Psychiatry, 17, 135-154.

Schwartz, J. C., Costentin, J., Martres, M. P., Protais, P., \& BANDRY, M. (1978). Modulation of receptor mechanisms in the CNS: Hyper- and hyposensitivity to catecholamines. Neuropharmacology, 17, 665-685.
Segal, D. S., \& Mandel, A. J. (1974). Long-term administration of d-amphetamine: Progressive augmentation of motor activity and stereotypy. Pharmacology, Biochemistry \& Behavior, 2, 249-255.

StewarT, J., \& Eikelboom, R. (1987). Conditioned drug effects. In L. L. Iversen, S. D. Iversen, \& S. H. Snyder (Eds.), Handbook of psychopharmacology (Vol. 19). New York: Plenum Press.

Tilson, H. A., \& RECH, R. H. (1973). Conditioned drug effects and absence of tolerance to d-amphetamine induced motor activity. Pharmacology, Biochemistry \& Behavior, 1, 149-153.

Vasko, M. R., \& Domino, E. F. (1978). Tolerance development to the biphasic effects of morphine on locomotor activity and brain acetylcholine in the rat. Journal of Pharmacology \& Experimental Therapeutics, 207, 848-858.

VAUGHN, D. M., \& WiLcox, R. E. (1982). Chronic apomorphine administration increases basal in vivo striatal dopamine turnover and produces opposite effects on turnover after apomorphine and spiroperidol challenge. Pharmacologist, 24, 105.

Vezina, P., \& Stewart, J. (1984). Conditioning and place-specific sensitization of increases in activity induced by morphine in the VTA. Pharmacology, Biochemistry \& Behavior, 20, 925-934.

Walters, J. R., Bunney, B. S., \& Roth, R. H. (1975). Piribedil and apomorphine: Pre- and postsynaptic effects on dopamine synthesis and neuronal activity. Advances in Neurology, 9, 273-284.

WANG, R. Y. (1981). Dopaminergic neurons in the rat ventral tegmental area: III. Effects of d-and 1-amphetamine. Brain Research Reviews, 3, 153-165.

White, F. J., \& WANG, R. Y. (1984). Pharmacological characterization of dopamine autoreceptors in the rat ventral tegmental area: Microiontophoretic studies. Journal of Pharmacology \& Experimental Therapeutics, 231, 275-280.

ZAMBLE, E. (1973). Augmentation of eating following a signal for feeding in rats. Learning \& Motivation, 4, 138-147.

Zamble, E., Hadad, G. M., Mitchell, J. B., \& Cutmore, T. R. H. (1985). Pavlovian conditioning of sexual arousal: First- and secondorder effects. Journal of Experimental Psychology: Animal Behavior Processes, 11, 598-610.

\section{NOTE}

1. Within the conditioning literature, this elicitation of a US-mimicking response by stimuli other than the nominal CS is known as "sensitization," and has been shown to result from repeated presentation of the US (see Mackintosh, 1974, pp. 26-27). Within the drug literature, as we have seen in the present paper, sensitization refers to the enhanced response to the US, the drug itself. The subtle difference between the two phenomena so labeled should be kept in mind even while their similarities are considered.

(Manuscript received September 25, 1986; revision accepted for publication February $3,1987$. 